\title{
FLUORESCENCE OF ATOPIC ALLERGENS
}

\author{
L BERRENS \\ Department of Dermatology and Allergy, Academic Hospital, State University, Utrecht \\ The Netherlands
}

(Recetved 23 September 1966)

\begin{abstract}
Purified atopic allergens have been found to emit blue fluorescence upon irradiation with ultraviolet light of $365 \mathrm{~m} \mu$ wavelength The maximum of fluorescence is in the region $445-490 \mathrm{~m} \mu$ and the intensity is of the same order of magnitude for different atopic allergens. Synthetic model compounds, incorporatıng N-substıtuted 1-amino-1-deoxy-2ketoses and their enolic tautomers, exhibit similar fluorescence characteristics A study of the pH-dependence of fluorescence emission indicates both the 1,2-enol and 2,3-enediol tautomers to be involved, the latter compound probably contributing to fluorescence in the form of a cyclic structure

These results offer independent evidence for the incorporation of $\mathrm{N}$-glycosidically linked sugar in atopic allergens
\end{abstract}

\section{INTRODUCTION}

CURRENT STUDIES on the chemical and spectral properties of purified atopic allergens have suggested that these antigens are characterized by the incorporation of N-substituted 1-amino-1-deoxy-2-ketoses in the molecular structure. These structural units, embracing the site of $\mathrm{N}$-glycosıdic protein-sugar linkage, give rise to particular absorption peaks in the ultraviolet spectrum. ${ }^{(1,2)}$ Such linkages may be formed by Maillard reactions between free protein amino groups and reducing sugar under conditions of natural decomposition. Synthetic model compounds prepared in the laboratory were found to exhıbit many of the physico-chemical characteristics of atopic allergens. ${ }^{(1-3,8)}$

The literature on Maillard reactions contains some indications of fluorescent compounds being formed in the early stages of the reaction, $1 \mathrm{e}$. before the development of brown colour. ${ }^{(5)}$ To check the earlier conclusions on the participation of the Maillard reaction in the formation of atopic allergens it was therefore decided to study their possible fluorescence characteristics. It is the purpose of this paper to show that fluorescence is a common property among atopic allergens, the study of which permits a more sensitive and precise molecular identification of $\mathrm{N}$-substituted aminodeoxyketoses and their derivatives.

\section{MATERIALS AND METHODS}

The source of the allergens and model substances, and their preparation and properties, has been given in previous papers. ${ }^{(1,4)}$

Fluorescence emission was studied with the aid of the Ze1ss Spectrophotometer, type PMQ II, equipped with a special fluorescence attachment. Excitation energy in this instrument is provided by a constant energy, low-pressure mercury arc, from which the wavelength of excitation is isolated by means of filters inserted between the energy source and the cuvettes. Emitted light is observed at right angles to the exciting radiation and the spectral distribution of the fluorescent 
light is obtained by dispersion of the beam in a quartz monochromator. Cuvettes were either of glass (for $365 \mathrm{~m} \mu$ excitation) or of quartz (for $313 \mathrm{~m} \mu$ excitation), with clear windows at the sides and at the bottom. The (double-walled) cuvette housing was cooled during measurements by circulatıng tap water at $16-18^{\circ} \mathrm{C}$.

Fluorescence intensity has been expressed in arbitrary units, because meter readings depend on instrument settings and on a number of instrument variables. However, for purposes of quantitation and comparison, fluorescence intensity has also been expressed in terms of units of quinine bisulphate (in $0.1 \mathrm{~N}$ sulphuric acid, fluorescence maximum at $460 \mathrm{~m} \mu$ ), used as a standard.

The model compound $\epsilon$-amino[1-deoxy-D-fructosyl-(1)]-caproic acid (EACAF) was synthesized from $\epsilon$-aminocaproic acid and D-glucose by a modification of the method of Heyns and Paulsen. (6) The substance was purified by passage through a column of Dowex- $21 \mathrm{~K}$ in the $\mathrm{HSO}_{3}^{-}$form as described by Adach1 ${ }^{(7)}$; the product emerging first from the column with $75 \%$ n-propanol (Identified by u.v.-scanning and by its property of reducing alkaline $\left.\mathrm{K}_{3} \mathrm{Fe}(\mathrm{CN})_{6}\right)$ was concentrated in vacuo, taken up in aqueous methanol and reprecipitated several times with ethylether.

\subsection{Atopic allergens}

\section{RESULTS}

Solutions of purfied atopic allergens in $0.01 \mathrm{~N} \mathrm{HCl}, 0.01 \mathrm{~N} \mathrm{NaOH}$ or in a phosphate buffer $\mathrm{pH} 7 \cdot 0(0.01 \mathrm{M})$ were found to emit blue to blue-green fluorescent light upon irradiation with energy of either $313 \mathrm{~m} \mu$ or $365 \mathrm{~m} \mu$ wavelength. The spectral distribution of the beam of fluorescent light obtained with $313 \mathrm{~m} \mu$ excitation was simular to that observed with $365 \mathrm{~m} \mu$ primary radiation, but the intensity of fluorescence was higher with the former. However, because the quality of the avallable $313 \mathrm{~m} \mu$ filter was inferior to that of the $365 \mathrm{~m} \mu$ filter, necessitating the introduction of complex correction factors, only the results obtained with excitation energy of $365 \mathrm{~m} \mu$ wavelength will be described here.

For most atopic allergens fluorescence intensity was higher at $\mathrm{pH} 2$ and $\mathrm{pH} 12$ than at neutral $\mathrm{pH}$, while, generally, for a given allergen the position of the peak in the fluorescence spectrum in acid medium was at a shorter wavelength than in alkaline solution. Moreover, fluorescence in alkalı had to be observed immediately after preparing the solution because the intensity rapidly decreased (see Results Section 3.3). Fluorescence spectra of a number of purified atopic allergens have been represented in Fig. 1.

It follows from Fig. 1 that fluorescence emission is in the range of $445-485 \mathrm{~m} \mu$, depending on $\mathrm{pH}$ and on the type of allergen involved. The position and height of the curve in alkali (Fig. 1, broken lines) relative to the curve in acid (Fig. 1, full lines) is uncertain because of the rapid fall in fluorescence intensity, which in some cases was found to amount to as much as $60 \%$ of the initial value. Obviously, however, the fluorescence spectra of different atopic allergens were quite similar; for further studies use was made of the stable fluorescence emission of allergen solutions at $\mathrm{pH} 2$.

The exact position of the fluorescence maximum within the range of 445-485 $\mathrm{m} \mu(\mathrm{pH} \mathrm{2,} \mathrm{excitation} 365 \mathrm{~m} \mu)$ depends on the nature of the allergen, 1.e. presumably 

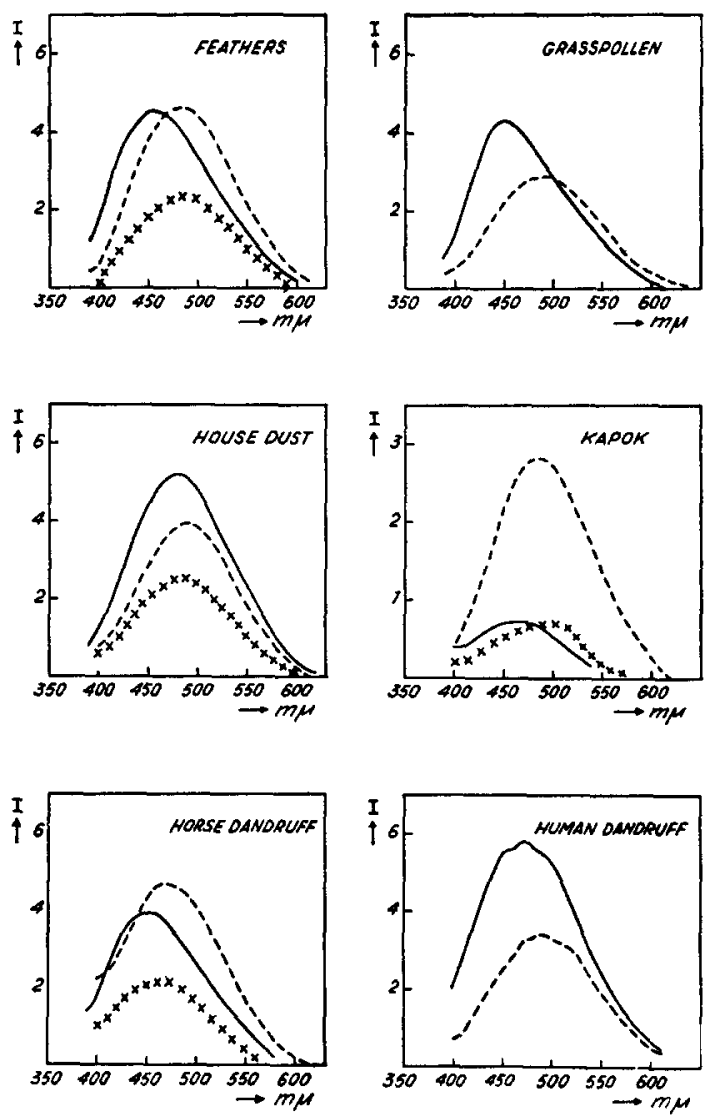

Fig 1 Fluorescence spectra of some purified atopic allergens at pH $2(001 \mathrm{~N}$ $\mathrm{HCl}$, full curves), $\mathrm{pH} 7$ (0 $01 \mathrm{M}$ phosphate buffer, crossed curves) and $\mathrm{pH} 12$ $\left(001 \mathrm{~N} \mathrm{NaOH}\right.$, broken curves) at $16-18^{\circ} \mathrm{C}$ Excitation $365 \mathrm{~m} \mu$ Fluorescence intensity in arbitrary units Feathers and kapok in $001 \%$ concentration, other allergens in $01 \%$

Table 1 Fluorescence maxima and fluorescence intensities of some purified atopic ALleRgens at pH $2(001 \mathrm{~N} \mathrm{HCl})$ Excitation: $365 \mathrm{~m} \mu(\mathrm{Hg})$

\begin{tabular}{lccc}
\hline Allergen & $\begin{array}{c}\text { Maximum of } \\
\text { fluorescence } \\
\text { emission } \\
(\mathrm{m} \mu)\end{array}$ & $\begin{array}{c}\text { Fluorescence intensity } \\
\text { of } 1 \mathrm{ppm} \\
\text { of allergen (1n ppm } \\
\text { quinine bisulphate) }\end{array}$ & $\begin{array}{c}\text { Concentration }(\mathrm{mg} / \mathrm{ml}) \\
\text { required to give a fluorescence } \\
\text { intensity equal to that of } 1 \\
\mu \mathrm{g} / \mathrm{ml} \text { quinine bisulphate }\end{array}$ \\
\hline House dust & 480 & $15 \times 10^{-4}$ & 7 \\
Human dandruff & 470 & $16 \times 10^{-4}$ & 6 \\
Kapok & 475 & $22 \times 10^{-4}$ & 5 \\
Liquorice & 470 & $35 \times 10^{-4}$ & 3 \\
Ipecac & 485 & $30 \times 10^{-4}$ & 8 \\
Tomato & 460 & $12 \times 10^{-4}$ & 9 \\
Horse dandruff & 455 & $11 \times 10^{-4}$ & 8 \\
Trichophytin & 460 & $51 \times 10^{-4}$ & 3 \\
Grass pollen & 450 & $13 \times 10^{-4}$ & 1 \\
Hay & 485 & $35 \times 10^{-4}$ & 3 \\
Feathers & 460 & $132 \times 10^{-4}$ & \\
\hline
\end{tabular}


on the ratio of the tautomeric 1,2- and 2,3-enol forms of the 1-amino-1-deoxy-2ketoses incorporated within the molecular structure (compare Results Section 3.3 and Discussion). The wavelengths corresponding to the fluorescence maxima are listed in Table 1.

The intensity of fluorescence for most atopic allergens was not very impressive. Moreover, in some deep brown allergen solutions considerable self-absorption of fluorescent light occurred; in these cases fluorescence was observed in $0.01 \%$ solutions rather than in the $0.1 \%$ solutions made up normally, and extra amplification of the instrument detectors was required. Because of the difference in the degree of coloration between the allergen solutions, and because fluorescence emission is not readily expressible in absolute units, fluorescence intensities of atopic allergens, given in Table 1, have been expressed in units of quinine bisulphate, for convenience, two methods of calculation have been applied.

It follows from Table 1 that fluorescence of the allergens is about 10,000 times less intense than the light emission of quinine bisulphate, on an equal weight basis. Estımating the mean molecular weight of atopic allergens at approximately 35,000 , the fluorescence yield of the allergens would be about 100 times less, on a molecular basis, than that of quinine bisulphate. Since, with most instruments, the lower limit of sensitivity for the fluorimetric assay of quinine sulphate is at about $0.01 \mu \mathrm{g} / \mathrm{ml}$, it may be concluded from Table 1 that atopic allergens may still be detected by their fluorescence in solutions of $0001-0.01 \%$ concentration; this is at least 10 times more sensitive than the assay by $u$ v. absorption.

Attempts at discovering significant correlations between the extınction coefficients of atopic allergens at 305,325 and $350 \mathrm{~m} \mu$, and their fluorescence intensity at 445 or at $490 \mathrm{~m} \mu$ (excitations $313 \mathrm{~m} \mu$ and $365 \mathrm{~m} \mu$ ) falled Likewise, no correlation existed between these extinction coefficients and the ratio of fluorescence intensities at 445 and $490 \mathrm{~m} \mu$; there was no simple relationship between the extinction ratio $\mathrm{E} 300 / \mathrm{E} 350$ and the fluorescence ratio $\mathrm{F} 445 / \mathrm{F} 490$.

\section{Model compounds}

A number of model compounds, found useful in the elucidation of structures suspected to be incorporated in atopic allergens $s^{(1,2,8)}$ were prepared for studying their fluorescence characteristics. These consisted of crystalline proteins reacted with D-ribose at $50^{\circ}$ in neutral aqueous solution, followed by dialysis and lyophilization; the products obtained were analysed and found to incorporate $\mathrm{N}^{e}$-(lysyl)-1-amino-1-deoxy-2-ketoses. . $^{(1,2,8)}$ The following substances were used: poly-L-lysine (PL), $M=75000,1-(\mathrm{N})$-deoxyribulose-polylysine (PLR); cryst. ovalbumin (OV); 1 -(N)-deoxyribulose-ovalbumin (OVR); cryst. bovine $\beta$-lactoglobulın (BL); $\beta$-lactoglobulin isolated from cow's milk according to Aschaffenburg and Drewry(日) but not crystallized (BLG); 1 -(N)-deoxyribulose- $\beta$-lactoglobulın (BLGR); human serum albumın, $3 \times$ cryst. (HSA); 1 -(N)-deoxyribulosehuman serum albumin (HSAR); human serum albumin control (HSAC) submitted to the same procedure as HSAR but in the absence of ribose; crystalline trypsin, pepsin and lysozyme.

These synthetic high molecular weight protein-sugar model compounds were all found to exhibit identical fluorescence characteristics. irradiation of dilute $(0.1 \%)$ 

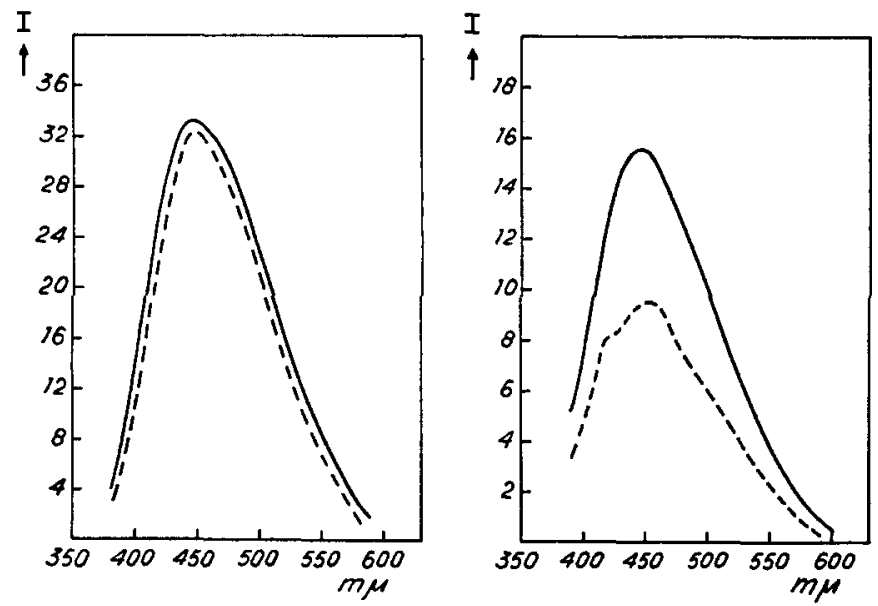

FIG. 2. Fluorescence spectra of two model compounds Excitation $365 \mathrm{~m} \mu$. Fluorescence intensity in arbitrary units.

Left 1-(N)-deoxyribulose- $\beta$-lactoglobulin (BLGR) $01 \%$ at $\mathrm{pH} 2$ (full curve) and pH 7 (broken curve).

Right $\cdot 1$-(N)-deoxyribulose-human serum albumin (HSAR) $01 \%$ at pH 2 (full curve) and pH 7 (broken curve).

TABle 2 * FluORESCENCE MAXIMA AND FLUORESCENCE INTENSITIES OF SOME CRYSTALLINE PROTEINS AND PROTEIN-SUGAR MODEL COMPOUNDS $(x)$ at $\mathrm{pH} 2(001 \mathrm{~N} \mathrm{HCl})$ EXCITATION: $365 \mathrm{~m} \mu(\mathrm{Hg})$

\begin{tabular}{lccc}
\hline \multicolumn{1}{c}{ Substance } & $\begin{array}{c}\text { Maximum of } \\
\text { fluorescence } \\
\text { emission } \\
(\mathrm{m} \mu)\end{array}$ & $\begin{array}{c}\text { Fluorescence } \\
\text { intensity of } \\
\text { ppm substance } \\
\text { (1n ppm } \\
\text { quinine bisulphate) }\end{array}$ & $\begin{array}{c}\text { Concentration (mg/ml) } \\
\text { required to give a } \\
\text { fluorescence intensity } \\
\text { equal to that of 1 } \mu \mathrm{g} / \mathrm{ml} \\
\text { quinine bisulphate }\end{array}$ \\
\hline B-lactoglobulin BL (cryst) & - & - & - \\
BLG & 450 & $03 \times 10^{-4}$ & 33 \\
$\times$ BLGR & 450 & $97 \times 10^{-4}$ & 1 \\
Human serum albumin HSA & 450 & $05 \times 10^{-4}$ & 20 \\
HSAC & 445 & $09 \times 10^{-4}$ & 11 \\
$\times$ HSAR & 445 & $45 \times 10^{-4}$ & 2 \\
Ovalbumin OV & 455 & $03 \times 10^{-4}$ & 33 \\
$\times$ OVR & 445 & $44 \times 10^{-4}$ & 2 \\
Polylysine PL & -5 & - & 2 \\
$\times$ PLR & 450 & $44 \times 10^{-4}$ & 25 \\
Pepsin & 455 & $04 \times 10^{-4}$ & 100 \\
Trypsin & 455 & $01 \times 10^{-4}$ & 100 \\
Lysozyme & 455 & $01 \times 10^{-4}$ & 2 \\
\hline
\end{tabular}

- Abbreviatıons $\beta$-lactoglobulın (BLG), 1-(N)-deoxyribulose- $\beta$-lactoglobulın (BLGR); human serum albumin control (HSAC), 1-(N)-deoxyribulose-human serum albumin (HSAR); ovalbumın (OV), 1-(N)-deoxyribulose-ovalbumın (OVR), 1-(N)-deoxyribulosepolylysine (PLR)

solutions at $\mathrm{pH} 2, \mathrm{pH} 7$ or $\mathrm{pH} 12$ produced a bright blue fluorescence, the spectral distribution of which was similar among the different models. Two examples are given in $F_{1}$. 2. These fluorescence spectra, moreover, closely resembled those of 
purified atopic allergens, with the restriction that the position of the fluorescence peak for the model compounds tended to be in the shorter range of $445-460 \mathrm{~m} \mu$. This might be due to the relatively short time allowed for the protein-sugar interaction in the preparation of these model substances, ${ }^{(3)}$ limiting thus the tendency of the 1,2-enol of the amınodeoxyketose to rearrange into the 2,3-enediol tautomer (see Results Section 33 and Discussion).

The position of the fluorescence peaks of model compounds has been given in Table 2, together with the relative intensities. Fluorescence intensity of the model substances is of the same order of magnitude as observed for atopic allergens

It has already been shown during a study of the $u$ v. absorption spectra of allergens and model compounds ${ }^{(1,2)}$ that the optıcal properties of these high-molecular weight substances are essentially due to the lysyl-sugar residue. the low molecular analogues of this structural unit exhibit similar u.v. absorption characteristics. Likewise, the compound $\epsilon$-amino-[1-deoxy-D-fructosyl-(1)]-caproic acid, closely resembling the smallest unit common to the allergens and models, possesses similar fluorescence characteristics $\left(F_{1} g .3\right)$. In the reaction of n-amylamine and D-ribose ${ }^{(1,2)}$

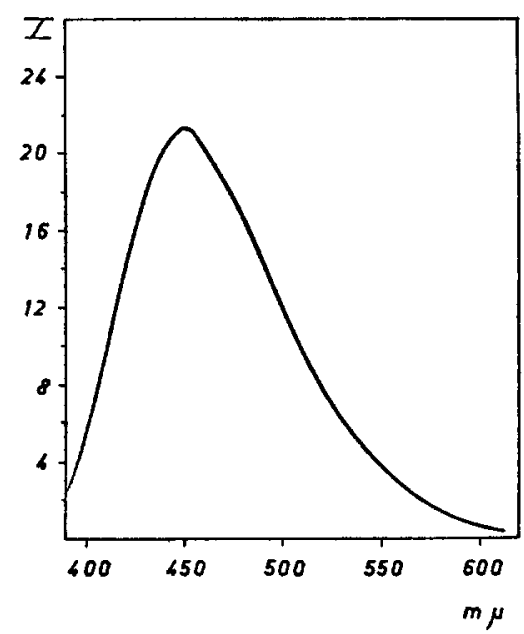

Fig 3. Fluorescence spectrum of $01 \% \mathrm{~N}$-(1-deoxy-1-D-fructosyl)- $\epsilon$-aminocaproic actd at pH $2(001 \mathrm{~N} \mathrm{HCl})$ Excitation $365 \mathrm{~m} \mu$ Fluorescence intensity in arbitrary units

at room temperature and $\mathrm{pH} \mathrm{7,} \mathrm{fluorescence} \mathrm{at} 445 \mathrm{~m} \mu$ could readily be observed to develop at a faster rate than the appearance of the u.v.-maxımum at $305 \mathrm{~m} \mu$ and preceding visible brown colouration. This observation is in accordance with the results of Burton $e^{t}$ al $^{(5)}$ and confirms the association of the property of fluorescence with the reactive intermediates in the early stages of the Maillard reaction.

\subsection{Influence of $p H$}

Some fluorescence spectra of atopic allergens at different $\mathrm{pH}$-values have already been shown in Fig. 1. The intensity of fluorescence at $\mathrm{pH} 7$ (phosphate buffer) was normally found to be lower than at $\mathrm{pH} 2$ and $\mathrm{pH} 12$, while the spectra of freshly prepared solutions at $\mathrm{pH} 12$, if scanned without delay, in a few cases were at a higher 
level of intensity than at $\mathrm{pH} 2$. However, the maxımum of fluorescence at $\mathrm{pH} 12$ in most cases was at a longer wavelength than noted for the same compound in acid medium. The fluorescence of solutions at $\mathrm{pH} 12$ rapidly faded, a reduction of over $50 \%$ of the initial value usually occurring in less than $30 \mathrm{~min}$. The same phenomenon was observed with solutions of atopic allergens and of (high-molecular and low-molecular weight) model compounds alike. After the rapid immediate fall of intensity, fluorescence emission remained at a steady minimum for at least $1 \mathrm{hr}$. Meter readings then showed a tendency to rise to higher values due to effects of light scattering in solutions of increasing turbidity. The latter phenomenon is interpreted as indicating the instability of allergens in highly alkaline solution and 1s supported by the proposed mechanism for inactivation ${ }^{(4)}: \beta$-elimination of the lysine-linked sugar resıdue, leaving an essentıally denatured unstable protein or glycoprotein.
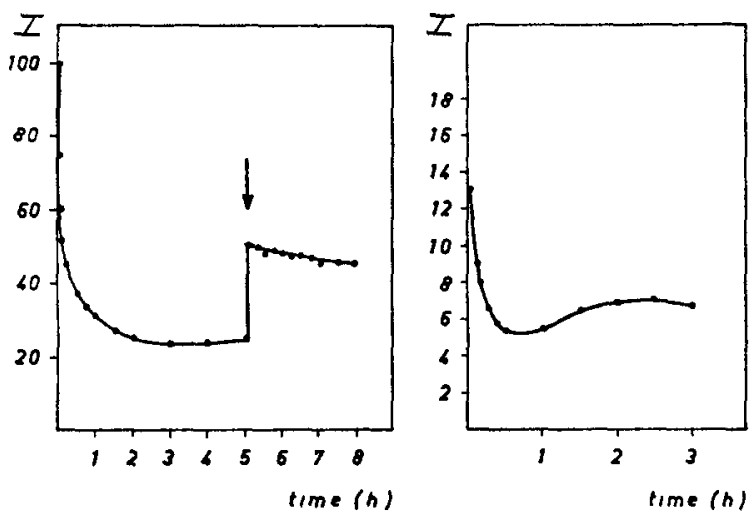

Fig 4. Left fluorescence emission at $445 \mathrm{~m} \mu$ of $01 \% \mathrm{HSAR}$ in $0.01 \mathrm{~N} \mathrm{HCl}$, 2 drops of $1 \mathrm{~N} \mathrm{NaOH}$ added to cuvette volume $(35 \mathrm{ml})$ at zero tıme, 2 drops of $4 \mathrm{~N} \mathrm{HCl}$ added after $5 \mathrm{hr}$ (indicated by arrow) Excitation $365 \mathrm{~m} \mu$.

Right: fluorescence emission at $480 \mathrm{~m} \mu$ of $01 \%$ ipecac allergen in $001 \mathrm{~N}$ $\mathrm{HCl} ; 2$ drops of $1 \mathrm{~N} \mathrm{NaOH}$ to cuvette volume $(35 \mathrm{ml})$ added at zero time Excitation $365 \mathrm{~m} \mu$. Fluorescence intensities in arbitary units.

The phenomenon of fading fluorescence is easily reproducible though not completely reversible. Thus, the addition of a drop of concentrated $\mathrm{NaOH}$ to a solution of an allergen or model compound resulted in a rapid decrease of fluorescence, but the subsequent acidification with conc. $\mathrm{HCl}$, although effecting a rise, did not completely restore the original fluorescence intensity (Fig. 4).

The shift of the fluorescence maximum towards longer wavelength could indeed be followed by rapidly scanning a section of the fluorescence spectrum in the region 445-490 during the first $20 \mathrm{~min}$ after the addition of alkal. In contrast, fluorescence emission at $\mathrm{pH} 2$ proved to be quite stable, decreasing only slightly (less than 10\%) even after several hours at room temperature.

The positions of the maxima of fluorescence for atopic allergens at $\mathrm{pH} 2$ and $\mathrm{pH}$ 12 are listed in Table 3, together with the ratio of fluorescence intensities at 445 and $490 \mathrm{~m} \mu$. The general trend towards lower ratios in alkali would seem to indicate the participation of two fluorescent structures, one of these (peak $445 \mathrm{~m} \mu$ ) being converted into the other $(490 \mathrm{~m} \mu)$ upon alkalınızation. 
Table 3 Fluorescence maxima at pH $2(001 \mathrm{~N} \mathrm{HCl})$ and pH $12(0.01 \mathrm{~N} \mathrm{NaOH})$ of some PURIFIED ATOPIC ALLERGENS AND SYNTHETIC PROTEIN-SUGAR MODEL COMPOUNDS, TOGETHER WITH THE RATIO OF FLUORESCENCE INTENSITIES AT 445 AND $490 \mathrm{~m} \mu$

\begin{tabular}{lcccc}
\hline \multicolumn{1}{c}{ Substance } & Max. at pH 2 & Max. at pH 12 & $\begin{array}{c}\text { F 445/F 490 } \\
\text { at pH 2 }\end{array}$ & $\begin{array}{c}\text { F 445/F 490 } \\
\text { at pH 12 }\end{array}$ \\
\hline HSAC & 445 & 445 & 139 & 136 \\
HSAR & 445 & 455 & 134 & 1.20 \\
BLG & 450 & 460 & 111 & 108 \\
BLGR & 450 & 450 & 128 & 136 \\
OV & 455 & 455 & 128 & 133 \\
OVR & 445 & 450 & 159 & 147 \\
Trichophytın & 470 & 470 & 096 & 089 \\
House dust & 480 & 490 & 080 & 065 \\
Kapok & 465 & 485 & 116 & 071 \\
Feathers & 455 & 485 & 113 & 076 \\
Hay & 470 & 470 & 083 & 081 \\
Ipecac & 485 & 480 & 078 & 081 \\
Liquonce & 470 & 490 & 090 & 058 \\
Horse dandruff & 455 & 465 & 126 & 086 \\
Human dandruff & 470 & 485 & 090 & 062 \\
Grass pollen & 450 & 485 & 131 & 071 \\
\hline
\end{tabular}

Spectra of solutions at $\mathrm{pH} 12$ observed $1 \mathrm{hr}$ after preparation

Abbreviations see key to Table 2

Similar observations hold for the high-molecular model compounds and for EACAF. It has already been deduced from the relevant u.v. absorption spectra ${ }^{(4)}$ that the 1,2-enolic tautomer of the $\mathrm{N}$-substituted 1-amino-1-deoxy-2-ketoses, with its absorption peak at $305 \mathrm{~m} \mu$, is converted under alkaline conditions into the 2,3-enediol form, absorbing at longer wavelengths. Similarly, the results reported here would be consistent with two fluorescence maxima, the $445 \mathrm{~m} \mu$ peak being due to the 1,2-enol and the maximum at 490 being attributable to the 2,3-enediol structure.

Finally, the fluorescence spectra were studied of a few allergens and model compounds in solutions at $\mathrm{pH} 2,3,5,6,7,8,10$ and $12(0.01 \mathrm{~N} \mathrm{HCl}$ for $\mathrm{pH} \mathrm{2,}$ sodium phosphate-citric acid buffer $0.01 \mathrm{M}$ for $\mathrm{pH} 3$ and $5, \mathrm{Na}_{2} \mathrm{HPO}_{4} / \mathrm{NaH}_{2} \mathrm{PO}_{4}-$ buffer $0.01 \mathrm{M}$ for $\mathrm{pH} 6,7$ and 8 , glycine- $\mathrm{NaOH}$ buffer $0.01 \mathrm{M}$ for $\mathrm{pH} 10,0.01 \mathrm{~N}$ $\mathrm{NaOH}$ for $\mathrm{pH} 12$ ). In the range of $\mathrm{pH} 2-7$ the intensity of fluorescence emission (excitation $365 \mathrm{~m} \mu$ ) gradually decreased, rising again in the region $\mathrm{pH} \mathrm{7-8}$ and settling at a level below that at $\mathrm{pH} 2$, but higher than at $\mathrm{pH} 7$. Fluorescence intensity then remained at a steady level between $\mathrm{pH} 8$ and 10; above $\mathrm{pH} 10$ fluorescence emission sharply declined.

These observations may be interpreted in terms of shifts in the equilibrium between the 1,2-enol, and 2,3-enediol forms of the N-substituted 1-amino-1deoxy-2-ketoses (see Discussion).

\section{DISCUSSION}

The association of the property of fluorescence with simple aliphatic open-chain compounds is of rare occurrence. ${ }^{(10)}$ Because the characteristic features of fluorescence emission of atopic allergens are also encountered with synthetic protein- 
sugar model compounds, it is justifiable to infer that these two groups of substances are related through groups of similar structure. Since the synthetic models solely differ from their non-fluorescent parent compounds by the incorporation of lysyl-sugar residues, and because the particular features of fluorescence emission may also be demonstrated with the relevant low-molecular weight analogues, the present results provide new evidence for simılar $\mathrm{N}$-substituted 1-amino-1-deoxy2-ketoses in the molecular structure of atopic allergens.

The experimental data invite attempts at a more precise identification of the particular structures involved. Thus, the results suggest two structures as the main contributors to fluorescence, viz. the 1,2-enol and the 2,3-enediol of the aminodeoxyketose; the 2-keto form probably does not participate, because in that case the fluorescence yield for the compound N-(1-deoxy-1-D-fructosyl)- $\epsilon$-aminocaproic acid (in aqueous solution equilibrating with low concentrations of its enolic tautomers) should have been much higher than actually observed.(3) Assuming the 1,2-enolic tautomer to fluoresce maximally at about $445 \mathrm{~m} \mu$, and the 2,3-enediol

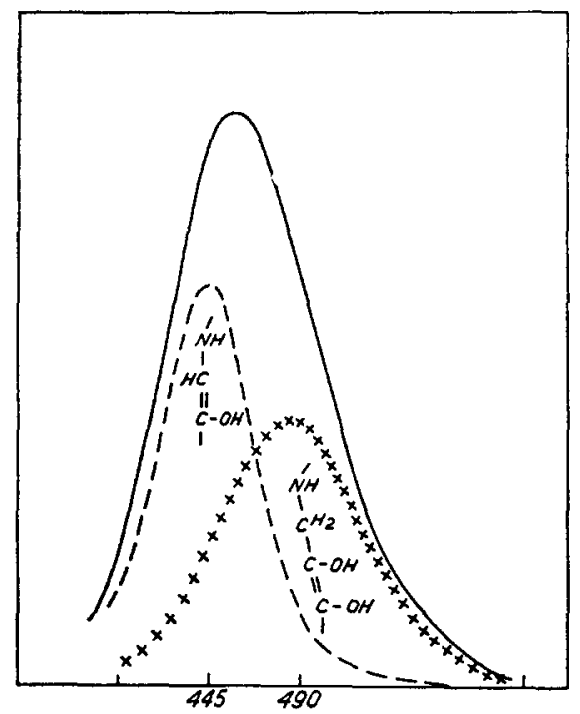

FIG. 5 Schematic representation of two main fluorescent tautomers of $\mathrm{N}$-substituted 1-amino-1-deoxy-2-ketoses in atopic allergens contributing to the over-all fluorescence emission $(1,2$-enol at $445 \mathrm{~m} \mu, 2,3$-enediol at $490 \mathrm{~m} \mu)$.

at $490 \mathrm{~m} \mu$, as indicated schematically in Fig. 5, a satisfactory model obtains for explaining the $\mathrm{pH}$-dependency of fluorescence. Increasing the $\mathrm{pH}$ in the range of 2-7 would convert the (highly fluorescent) 1,2-enol into its corresponding 2-keto form (Amadori product) and, subsequently, into the 2,3-enediol tautomer. The latter substance is probably stabilized between $\mathrm{pH} 7$ and 10 by the formation of a salt-bridge between the (epsilon)-nitrogen atom and the acidic hydroxyl at carbon atom C-3 of the sugar residue. Atomic (Stewart) models show that, in fact, the C-3 hydroxyl and the $\mathrm{N}$-atom are very close together, faclitating ring closure. The loss of positive charge on the nitrogen atom over $\mathrm{pH} 10$ and, concurrently, of the 
stabilizing cyclic ( $p$ seudo-isoxazoline) configuration, leaves an open-chain 2,3enediol which, like other reductones of related structure, would be very unstable under these conditions. ${ }^{(3,11,12)}$ The proposed chemical system thus accounts for the decline of fluorescence in strongly alkalıne solution, and for its irreversibility. It may be suggested that the position of the fluorescence peak of atopic allergens in the region $445-490 \mathrm{~m} \mu$ logically depends on the initial ratio of the $1,2-$ and $2,3-$ enols in the molecular structure.

The fluorescence of purified atopic allergens has been considered for possible application in the in vitro assay for reaginic antibodies in the sera of atopic individuals. Fluorescence quenching of allergens added to these sera was indeed observed; likewise, fluorescence emission of standard solutions of EACAF added to human allergic sera rapidly decreased. Nevertheless, methods based on this phenomenon are subject to criticism on theoretical grounds, while their practical application proved impossible because of large experimental errors introduced by light-scattering due to the different degree of turbidity of reaginic sera.

Finally, it should once again be emphasized that the property of fluorescence described here is, primarily, characteristic of Maillard-type products ' 1 ts association with purified atopic allergens merely proves these antigens to fall into the same category. Apparently, for antigenic and allergenic activity additıonal requirements are to be met.

Acknowledgement-The technical assistance of Miss H. de Lange is gratefully acknowledged.

\section{REFERENCES}

1 Berrens L. and Bleumink E , Int. Archs Allergy appl Immun 28, 150 (1965)

2 BerRens L. and Bleumink E, Recl Trav chim. Pays-Bas Belg. 85, 59 (1966).

3 BerRens L., Recl Trav chim Pays-Bas Belg. 85, 1117 (1966).

4 BERRENS L , Immunochemistry 4, 37 (1967)

5 Burton H S., McWeeney D. J, Pandhi P. N and Biltcliffe D. O., Nature, Lond 196,948 (1962)

${ }^{6}$ Heyns $\mathrm{K}$ and Paulsen H , Liebigs Ann Chem 622, 160 (1959).

7 Adachi S, Anal Brochem 9, 150 (1964)

8 BleuminK E. and Berrens L , Nature, Lond 212, 541 (1966)

9 Aschaffendurg R. and Drewry J., Biochem $f$ 65, 273 (1957).

10 WeIssberger L., Techniques of Organic Chemistry, Vol IX, Chemical applications of spectroscopy, Chapter VI, p 707 Interscience (1956)

11 ANET E. F L J, Advances in Carbohydrate Chemistry (Edited by Wolfrom M. L. and Stuart Tipson R ), Vol. 19, p. 181. Academic Press, (1964)

12 EISTERT B., von Braun J and H. KRóPER ' Organische Cheme, Band I, p 519 S Hirzel (1954) 